\title{
Entre normas socioculturais e dietéticas: o almoço para nutricionistas e mulheres leigas brasileiras, espanholas e francesas
}

\author{
Between sociocultural and dietary norms: \\ the lunch for Brazilian, Spanish and French dietitians and laywomen
}

${ }^{1}$ Université de Toulouse Jean-Jaurès (CERTOP UMR 5044/CNRS). Maison de la Recherche, 5, allée Antonio Machado. F-31058 Toulouse Cedex 9 França.

ma.prata@gmail.com

\begin{abstract}
Over the course of the past few decades, the scientific rationale on nutrition has consolidated, intensifying the dissemination of dietary nor$m s$ that dictate what and when to eat to guarantee good health. There is an increase in the interconnection between dietary norms and sociocultural norms. This study seeks to understand this link through the analysis of discourses of Brazilian, Spanish and French dietitians and laywomen. With this in mind, the sociocultural and dietary norms related to the midday meal were analyzed. Comparative and qualitative synchronous methodology, based on 131 semi-structured individual interviews, was used. The discourses of the informants were cross-checked with the public health messages on nutrition of each country. The analyses revealed that each nationality has particular codes that define the specifics of each meal, from the sociocultural and dietary point of view. The definition of a "healthy" meal depends on factors ranging from the nutritional and physiological to the social, cultural and symbolic dimensions linked to each meal model, determining the rituals, frequency, use and classification of food products. Thus, the norms that define what is perceived as healthy similarly result from sociocultural normative systems.
\end{abstract}

Key words Social norm, Dietary norm, Meals, Healthy eating, Qualitative research
Resumo Nas últimas décadas, a racionalidade científica nutricional consolidou-se, intensificando uma difusão de normas dietéticas que ditam o que e como comer para garantir uma boa saúde. Observa-se a ascensão de uma articulação entre normas dietéticas e normas socioculturais. Este estudo busca compreender esta articulação através da análise de discursos de nutricionistas e de mulheres leigas brasileiras, espanholas e francesas. Para tanto, analisou-se as normas socioculturais e dietéticas do almoço. Uma metodologia comparativa sincrônica e qualitativa, baseada em 131 entrevistas individuais semiestruturadas, foi utilizada. Os discursos das informantes foram confrontados com as mensagens nutricionais de saúde pública de cada país. As análises revelaram que cada nacionalidade possui códigos particulares que definem as modalidades de refeição, tanto do ponto de vista sociocultural como dietético. A definição de refeição "saudável" depende de fatores que vão do nutricional e fisiológico às dimensões sociais, culturais e simbólicas vinculadas a cada modelo alimentar, determinando rituais, temporalidades, usos e a classificação dos alimentos. Assim sendo, as normas que definem o que é percebido como saudável resultam também de sistemas normativos socioculturais.

Palavras-chave Norma social, Norma dietética, Refeições, Alimentação saudável, Pesquisa qualitativa 


\section{Introdução}

O ato de se alimentar é um "fato social total" que participa da construção das identidades sociais ${ }^{2,3}$. Durante o último século, parte dos sistemas normativos de regulação social que estruturavam a alimentação enfraqueceram-se, enquanto outros sistemas normativos emergiram, gerando uma situação de "cacofonia alimentar", marcada pela coexistência de diferentes discursos normativos ${ }^{2}$. Entre esses discursos, destacam-se aqueles relacionados ao campo médico. O processo de medicalização da alimentação intensificou-se ${ }^{3}$, consolidando a racionalidade científica nutricional ${ }^{4,5}$ e a difusão de normas dietéticas que ditam o que comer para garantir uma boa saúde ${ }^{6}$. A biomedicina moderna, na qual as ciências nutricionais baseiam-se, está inserida na tradição do positivismo científico e, nesta perspectiva, é normatizadora e considera que os conhecimentos se inscrevem em leis universais ${ }^{7}$. Embora os discursos de saúde pública busquem gradualmente adequar-se aos contextos socioculturais, ${ }^{8,9}$, persiste, ainda, no âmbito das ciências nutricionais, uma racionalização do "comer saudável" fundada neste paradigma mecanicista e tecnicista que tem como critérios a objetividade, a mensurabilidade e a generalização dos dados a diferentes situações socioculturais ${ }^{10}$. Neste contexto, observa-se uma concorrência e uma articulação entre normas dietéticas e normas socioculturais, que permeiam as diferentes dimensões do comer ${ }^{11}$.

Este estudo busca compreender as relações entre normas socioculturais e dietéticas por meio da análise de discursos de nutricionistas, profissionais cada vez mais implicados na difusão das normas dietéticas ${ }^{12}$, e de mulheres leigas, de nacionalidades brasileira, espanhola e francesa. Com este propósito, serão analisadas as normas do almoço, considerado como uma "verdadeira refeição" no Brasil, na Espanha e na França ${ }^{3,13,14}$, dado que é uma tomada alimentar altamente institucionalizada e sobre a qual as normas socioculturais relativas à combinação e sequência dos pratos é bem definida ${ }^{15,16}$.

Na perspectiva socioantropológica, a refeição está associada a um sistema social mais amplo, ligado a outros sistemas organizados ${ }^{17,18}$. Longe de representar somente uma forma de responder às necessidades fisiológicas, a refeição é um "fato social" no âmago de um sistema complexo envolto a motivações materiais, sociais, psicológicas e simbólicas ${ }^{15}$. Essas motivações inscrevem-se em um sistema normativo que determina a forma de comer e a vida social e que revela a difusão de um modelo alimentar ${ }^{19}$. As normas que definem o formato da refeição, ou seja, a composição, organização e sequência dos pratos ${ }^{16,20}$, assim como a própria concepção de refeição, variam no tempo e de acordo com os diferentes grupos socioculturais $^{3,16,20}$. Kahma et al. ${ }^{20}$ observam que as percepções do que é uma refeição transformaram-se em consequência dos novos fenômenos sociais, entre os quais a ascensão da nutrição e a intensificação das preocupações com a saúde.

A maioria dos estudos sobre a refeição tem se limitado à sua dimensão nutricional, e a articulação de sistemas normativos foi pouco explorada. Alguns estudos interessaram-se pelas normas socioculturais da refeição $0^{20-23}$, pelas discrepâncias entre normas e práticas ${ }^{3,13}$ e pela adequação das práticas às prescrições dietéticas da refeição ${ }^{24,25}$. Esses trabalhos, realizados principalmente no contexto europeu, não exploraram as normas de nutricionistas, e não compararam a articulação de sistemas normativos entre estes profissionais e indivíduos leigos de realidades socioculturais distintas, considerando tanto as normas socioculturais como as normas dietéticas por eles interiorizadas. Conhecer as normas socioculturais e dietéticas de nutricionistas e indivíduos leigos é, contudo, fundamental para a compreensão das práticas alimentares e para a elaboração de recomendações conformes aos contextos socioculturais, facilitando sua aplicação pelos indivíduos. Algumas questões orientaram este estudo: quais são as normas socioculturais e dietéticas do almoço de nutricionistas e mulheres leigas brasileiras, espanholas e francesas? As normas socioculturais influenciam as concepções de uma refeição saudável?

A abordagem adotada revela, de um lado, a influência das normas socioculturais sobre as nutricionistas e, de outro, a influência dos discursos nutricionais sobre a população leiga. $\mathrm{O}$ trabalho interroga sobre a homogeneização das problemáticas alimentares tanto na sociedade como no campo nutricional-científico, e usa uma abordagem interdisciplinar na articulação da socioantropologia da alimentação e da saúde. Uma socioantropologia das normas dietéticas é proposta, tal como sugere Grignon ${ }^{26}$ : "Reconstruir as condições sociais de produção destas normas e mostrar o que elas devem às particularidades do contexto no qual foram elaboradas"26(p.9) (tradução nossa).

\section{Metodologia}

Uma metodologia qualitativa baseada em entrevistas individuais semiestruturadas foi utilizada. 
Este método é pertinente para analisar as normas, as significações e os valores dos indivíduos ${ }^{27}$. Este estudo também foi construído a partir de uma abordagem comparativa sincrônica. A amostra foi definida em uma perspectiva inter e intracultural. As unidades de comparação foram determinadas através de uma escolha pragmática, dado a familiaridade com os grupos estudados, e de uma escolha estratégica, segundo a problemática da pesquisa ${ }^{28}$. A França, a Espanha e o Brasil foram selecionados de acordo com as características de suas normas alimentares ${ }^{3,13,14}$. Além disso, estes países desenvolveram, nas últimas décadas, políticas de saúde pública que definem as recomendações nutricionais de seus países ${ }^{8,29}$.

Dada a dificuldade de apreender a totalidade de um país em um estudo, é pertinente definir características demográficas $^{30}$. A amostra foi, assim, selecionada de acordo com o gênero, idade, profissão e/ou escolaridade. As mulheres são mais propensas a estabelecer a relação alimentação-saúde, a interiorizar normas dietéticas e a controlar a alimentação ${ }^{3,31}$. O estudo foi realizado em zonas urbanas (Toulouse na França, Barcelona na Espanha e São Paulo no Brasil) com francesas, espanholas e brasileiras divididas em dois grupos: um de nutricionistas mulheres e outro de mulheres leigas. Em relação às nutricionistas, trata-se de um grupo profissional composto majoritariamente por mulheres ${ }^{32}$. Apesar de diferenças quanto à história da profissão e à formação acadêmica, nos três países analisados a profissão do nutricionista é reconhecida por lei. O estudo foi limitado a nutricionistas que trabalham em consultórios, sem distinção de idade. O grupo leigo foi composto por estudantes universitárias e buscou-se uma amostra heterogênea em relação aos campos de estudo e ao tipo de instituição (privada/pública). Um critério de exclusão foi estudantes de Nutrição. Foram entrevistadas universitárias de 18 a 30 anos, considerando que as mulheres jovens são mais sensíveis às normas dietéticas ${ }^{3}$. Apesar das informantes serem referidas pela sua nacionalidade, os resultados não são representativos do conjunto da população, visto que as entrevistadas são parte de contextos específicos, seja do ponto de vista geográfico, social, da atividade exercida pelas nutricionistas e da escolaridade das universitárias.

O trabalho de campo foi realizado entre 2010 e 2015 . As participantes foram encontradas através: de internet (no caso das nutricionistas) usando palavras-chave ou nas páginas das associações profissionais; dos campi universitários (para as mulheres leigas); do entorno dos pesquisadores; do método bola de neve - informantes nos colocaram em contato com possíveis informantes. As participantes foram contatadas por e-mail ou telefone. Os objetivos do estudo foram explicados e verificou-se a disponibilidade para a realização de uma entrevista. Em cada país, 15 nutricionistas foram entrevistadas. No caso das mulheres leigas, 29 entrevistas foram realizadas na França, 32 na Espanha e 25 no Brasil. As entrevistas foram orientadas por um guia de entrevista em francês, espanhol e português, aprovado por pessoas nativas, constituído de quatro partes: (1) representações e práticas alimentares; (2) relação alimentação-saúde; (3) modelo corporal; (4) relação com o peso. Uma quinta parte sobre a atividade profissional incluía o guia destinado às nutricionistas. As entrevistas duraram entre 50 minutos e 2 horas, foram gravadas e transcritas.

A fase de transcrição permitiu realizar as primeiras observações. Segundo as recomendações de Blanchet e Gotman ${ }^{27}$, foi efetuada uma análise temática a partir de uma grade de análise criada de acordo com as problemáticas e hipóteses do estudo, bem como com os novos elementos que emergiram das entrevistas. Essa grade consistia em temas/categorias principais e temas/ categorias secundários mais específicos, a fim de decompor e codificar as informações o máximo possível. Essa grade foi construída de acordo com uma lógica vertical e horizontal, a fim de levar em consideração os casos individuais e as dimensões transversais às várias entrevistas.

$\mathrm{O}$ almoço foi abordado a partir das normas socioculturais e dietéticas. As normas socioculturais correspondem a um agregado de injunções que se enraízam nas tradições socioculturais e familiares, e que resultam da socialização do indivíduo em um determinado grupo ${ }^{3}$. A fim de identificar estas normas, interrogou-se: "Para você, o que é um verdadeiro almoço?”. Em relação às normas dietéticas, Poulain ${ }^{3}$ propõe uma definição considerando o processo de medicalização da alimentação:

Um conjunto de prescrições sustentadas por conhecimentos científico-nutricionais e difundidas por profissionais da saúde. Mais ou menos flutuantes, segundo as descobertas científicas, elas descrevem em termos quantitativos e qualitativos o que deve ser uma alimentação suscetivel de manter o comensal em um bom estado de saúde. ${ }^{3}$ (p.41) (tradução nossa).

Uma questão principal deu acesso às normas dietéticas: o que é uma alimentação saudável?. Os materiais que as nutricionistas oferecem a seus pacientes (como menus) também colaboraram na compreensão destas normas. Finalmente, os discursos das informantes foram confrontados 
com as mensagens de saúde pública. Para tanto, analisou-se, na França, o Programme National Nutrition Santé (PNNS); na Espanha, a Estrategia NAOS ${ }^{29}$; e no Brasil, o Guia Alimentar para a População Brasileira ${ }^{8}$. A análise do "formato de refeição" foi realizada com base nas duas formas de estrutura de refeição propostas por Lévi-Strauss ${ }^{3}$ : a sincrônica, na qual um prato ou uma série de pratos são dispostos simultaneamente, e a diacrônica, na qual diferentes pratos são servidos um depois do outro.

Este estudo foi aprovado pelo Comitê de Ética da Universidade de Toulouse. O consentimento informado foi obtido das participantes e a confidencialidade foi garantida.

\section{Resultados}

As principais categorias analíticas usadas para a compreensão das normas socioculturais e dietéticas do almoço foram, respectivamente, "verdadeira refeição" e "refeição saudável/equilibrada". Ambas tinham como subcategorias: temporalidade, convivialidade, contexto, formato, qualidade e dificuldades. Na primeira parte dos resultados, alguns elementos das normas socioculturais e dietéticas do almoço serão abordados de forma geral, seguidos da apresentação das normas relativas ao formato do almoço segundo cada nacionalidade.

\section{Normas socioculturais e normas dietéticas do almoço}

De acordo com os discursos das informantes, embora existam diferenças no nível normativo (tanto socioculturalmente como nutricionalmente) entre os três países quanto aos horários, tipo e número de refeições por dia (Quadro 1), a definição das refeições mais importantes é similar (café da manhã, almoço e jantar), assim como a hierarquização das refeições: o almoço ocupa um lugar mais preponderante no dia alimentar. Além disso, as informantes diferenciam as lógicas alimentares dos dias festivos e de trabalho/estudo; as normas apresentadas neste artigo referemse preponderantemente a este último contexto.

Quanto às normas socioculturais, as informantes das três nacionalidades reivindicam a importância de realizar o almoço seguindo regras precisas: é necessário comer uma "verdadeira refeição", um lugar adequado, e um tempo desconectado de outras atividades para se dedicar à comer. Esta "verdadeira refeição" seria constituída de preparações cozinhadas e que as infor- mantes associam a uma alimentação doméstica. Além disso, uma "verdadeira refeição" implica o compartilhamento, principalmente com pessoas com as quais existe vínculos afetivos. As dimensões temporais, espaciais, sociais e contextuais são, assim, importantes.

Em relação às normas dietéticas, as entrevistadas das três nacionalidades evocam frequentemente a noção de refeição equilibrada a fim de designar a refeição percebida como "saudável". Cabe notar que é geralmente o almoço e o jantar que são mencionados nos discursos sobre a alimentação saudável. Trata-se, assim, das tomadas alimentares sobre as quais pesam de forma mais importante as injunções médicas. A análise revela um discurso medicalizado, principalmente entre as nutricionistas e entre as brasileiras, de forma geral. Esta "refeição equilibrada" é descrita de forma quantitativa e qualitativa, geralmente sem que as dimensões hedonistas, gustativas e sociais sejam consideradas. Existe um consenso nas três nacionalidades em relação a alguns princípios que devem nortear uma alimentação saudável e que devem estar integrados na refeição: o equilíbrio, a moderação e a variedade. Quanto à qualidade, as informantes, principalmente espanholas e francesas, valorizam a origem e os modelos de produção dos alimentos como elementos de saudabilidade. As formas de preparação também são citadas, sobretudo pelas nutricionistas brasileiras, a fim de indicar como os alimentos devem ser cozinhados do ponto de vista dietético: é necessário privilegiar as preparações assadas, grelhadas e ao vapor em detrimento das frituras. As três nacionalidades também enfatizam uma dicotomia entre almoço energético/completo versus jantar leve/simplificado. O "almoço equilibrado" deve ser completo, pouco gorduroso e composto de três grupos alimentares: cereais, vegetais e proteínas.

Os discursos relativos ao "formato da refeição" revelam, dentro de cada país, normas socioculturais e dietéticas convergentes, que evidenciam padrões compartilhados tanto pelas nutricionistas como pelo grupo leigo de cada nacionalidade.

\section{Contexto francês}

Os discursos das nutricionistas e mulheres leigas francesas revelam que tanto a norma sociocultural como a norma dietética do almoço correspondem principalmente a uma estrutura diacrônica, completa, composta de uma entrada, um prato principal com acompanhamento, um queijo e/ou uma sobremesa. Uma outra descrição substitui a sobremesa e o queijo pela 
Quadro 1. Normas socioculturais e dietéticas do dia alimentar e do almoço interiorizadas pelas nutricionistas e mulheres leigas francesas, espanholas e brasileiras, e as recomendações de Saúde Pública.

\begin{tabular}{|c|c|c|c|}
\hline & Contexto francês & Contexto espanhol & Contexto brasileiro \\
\hline $\begin{array}{l}\text { Normas } \\
\text { socioculturais e } \\
\text { dietéticas relativas } \\
\text { à organização do } \\
\text { dia alimentar }\end{array}$ & $\begin{array}{l}3 \text { refeições } \\
\text { (café da manhã, almoço, jantar) }\end{array}$ & $\begin{array}{l}5 \text { refeições } \\
\text { (café da manhã, lanche da } \\
\text { manhã, almoço, lanche da } \\
\text { tarde, jantar) }\end{array}$ & $\begin{array}{l}\text { 5-6 refeições } \\
\text { (café da manhã, lanche } \\
\text { da manhã, almoço, } \\
\text { lanche da tarde, jantar, } \\
\text { ceia) }\end{array}$ \\
\hline $\begin{array}{l}\text { Normas } \\
\text { socioculturais do } \\
\text { almoço: } \\
\text { "verdadeiro } \\
\text { almoço" }\end{array}$ & $\begin{array}{l}\text {-Estrutura diacrônica. } \\
\text {-Composição: Entrada + prato } \\
\text { principal (proteína animal e prepa- } \\
\text { ração a base de cereal) + sobre- } \\
\text { mesa e/ou lácteos (queijo e/ou } \\
\text { iogurte). Pão de acompanhamento. }\end{array}$ & $\begin{array}{l}\text {-Estrutura diacrônica. } \\
\text {-Composição: "Primeiro } \\
\text { prato" (salada, sopa ou } \\
\text { preparação a base de } \\
\text { cereal) + "segundo prato" } \\
\text { (proteína animal) + } \\
\text { sobremesa. }\end{array}$ & $\begin{array}{l}\text {-Estrutura sincrônica. } \\
\text {-Composição: arroz } \\
\text { com feijão, salada, legu- } \\
\text { mes e carne ou frango. }\end{array}$ \\
\hline $\begin{array}{l}\text { Normas dietéticas } \\
\text { do almoço: } \\
\text { "refeição saudável/ } \\
\text { equilibrada" }\end{array}$ & $\begin{array}{l}\text {-Estrutura diacrônica. } \\
\text {-Composição: Entrada + pra- } \\
\text { to principal (proteína animal e } \\
\text { preparação a base de cereal) + } \\
\text { sobremesa e/ou lácteos (queijo e/ } \\
\text { ou iogurte). }\end{array}$ & $\begin{array}{l}\text {-Estrutura diacrônica. } \\
\text {-Composição: "Primeiro } \\
\text { prato" (salada, sopa ou } \\
\text { preparação a base de } \\
\text { cereal) + "segundo prato" } \\
\text { (proteína animal) + } \\
\text { sobremesa. } \\
\text {-Valorização da dicotomia } \\
\text { almoço/refeição energé- } \\
\text { tica versus jantar/refeição } \\
\text { leve. }\end{array}$ & $\begin{array}{l}\text {-Estrutura sincrônica. } \\
\text {-Composição: arroz } \\
\text { com feijão, salada, legu- } \\
\text { mes e proteína animal. } \\
\text {-"Prato colorido". } \\
\text {-Quantidades: “4 co- } \\
\text { lheres de arroz" / "duas } \\
\text { de arroz para uma de } \\
\text { feijão". }\end{array}$ \\
\hline $\begin{array}{l}\text { Recomendações } \\
\text { de Saúde Pública } \\
\text { relativas ao } \\
\text { almoço }\end{array}$ & $\begin{array}{l}\text {-Estrutura diacrônica. } \\
\text {-Composição: } 1 \text { porção de } \\
\text { verduras cruas e/ou acompanhadas } \\
\text { do prato principal, de carne, de } \\
\text { peixe ou de ovos, de cereais (pão } \\
\text { integral, arroz, batata assada, } \\
\text { massas, lentilhas, etc.), } 1 \text { produto } \\
\text { lácteo (queijo } 30 \mathrm{~g} \text {, um iogurte, } \\
\text { etc.), } 1 \text { fruta. } \\
\text {-Pão de acompanhamento e lácteo } \\
\text { no final da refeição*. }\end{array}$ & $\begin{array}{l}\text { Não apresenta } \\
\text { recomendação quanto ao } \\
\text { formato do almoço }\end{array}$ & $\begin{array}{l}\text {-Estrutura sincrônica. } \\
\text {-Composição: valori- } \\
\text { zação do prato de arroz } \\
\text { com feijão, verduras e } \\
\text { legumes (crus em sala- } \\
\text { das ou em preparações } \\
\text { cozidas ou refogadas), } \\
\text { proteína animal e so- } \\
\text { bremesa (frutas e doces } \\
\text { caseiros) }^{\star * *} \text {. }\end{array}$ \\
\hline
\end{tabular}

${ }^{\star}$ Fonte: Programme National Nutrition Santé (https://www.mangerbouger.fr/); ${ }^{\star \star}$ Fonte: AESAN (2005); ${ }^{\star * * F o n t e: ~ B r a s i l ~(2014) . ~}$

menção de um lácteo (Quadro 1). Segundo CR (nutricionista francesa, 31), uma "verdadeira refeição" corresponde a: "uma entrada, um prato, queijo ou iogurte e uma sobremesa". Segundo MA (francesa, 24), uma "refeição equilibrada" é: "uma entrada, prato principal e uma sobremesa pequena. Está perfeito. Como entrada uma salada, depois é verdade que é bom comer carne. Com macarrão, arroz, legumes ao vapor, está perfeito". Apesar das informantes também considerarem a refeição completa, valorizada socialmente, como a mais saudável, não se trata de comer em excesso. É necessário seguir a lógica da "boa" medida e distribuição dos grupos alimentares garantindo a variedade. Além disso, quando as francesas descrevem uma refeição equilibrada, elas mencionam a importância dos lácteos (io- gurtes e/ou queijos) no final da refeição. Este posicionamento é diferente do das nutricionistas e até mesmo das informantes leigas brasileiras, que declaram que é necessário, do ponto de vista dietético, evitar lácteos no final da refeição devido às interações nutricionais negativas que podem ocorrer.

Outro aspecto importante refere-se ao pão, mencionado como um elemento da "verdadeira refeição”. Às vezes as informantes não o citam espontaneamente, revelando que se trata de uma norma bem interiorizada, dada como evidente. De fato, o pão é considerado como um alimento essencial por um quarto das francesas entrevistadas. A noção francesa de refeição equilibrada também revela um posicionamento distinto quanto aos carboidratos, principalmente no 
caso do pão. Enquanto na Espanha, e sobretudo no Brasil, as informantes apresentam uma visão mais negativa deste grupo de alimentos, as francesas insistem sobre a importância da sua presença em cada refeição, e destacam que o pão pode estar associado a outro cereal: "os legumes, os produtos lácteos, os cereais têm que ter um pouco em cada refeição. Nós, a gente come cereal mais pão na França, nas minhas refeições, ao menos como eu aprendi como recém-nutricionista. No almoço você come macarrão ou arroz e também pão" (NV, nutricionista francesa, 22).

Este formato de refeição também integra as recomendações das nutricionistas entrevistadas e os discursos de saúde pública na França. As recomendações do PNNS abordam o almoço de forma qualitativa e quantitativa, assim como a partir de sua estrutura e composição. Segundo o PNNS, o almoço e o jantar podem ter a mesma composição (Quadro 1). Uma estrutura diacrônica (entrada, prato principal e sobremesa) também é indicada. Além disso, na página web do PNNS, é possível compor menus. A opção padrão corresponde a esta estrutura de refeição acompanhada de pão e de um lácteo.

\section{Contexto espanhol}

Para as espanholas entrevistadas, um "verdadeiro almoço" refere-se sobretudo a uma estrutura diacrônica e ternária: "é um primeiro prato, um segundo prato e uma sobremesa" (MI, nutricionista espanhola, 52) (Quadro 1). Esta "verdadeira refeição" é frequentemente associada à forma pela qual os pais, principalmente a mãe, comem: "com a minha mãe tudo era mais estruturado, sempre comíamos uma entrada, uma salada, sempre tinha hortaliças ou legumes e um segundo prato, carne ou peixe, e como sobremesa uma fruta" (VE, espanhola, 23). Cabe notar que as espanholas apreendem esta estrutura diacrônica diferentemente que as francesas. Elas nomeiam a entrada como o primeiro e o prato principal como o segundo, e os organizam a partir de uma lógica distinta. De acordo com a norma sociocultural, expressa pelas espanholas e observável nos restaurantes coletivos, o primeiro pode ser uma salada ou uma sopa, mas também cereais, como arroz ou massas. O segundo tem como elemento central uma proteína animal. As normas dietéticas seguem esta mesma lógica. De acordo com MB (espanhola, 22), uma "refeição equilibrada" é: "primeiro um pouco de salada, porque é bom para preparar o corpo ter um primeiro prato mais leve ou massas, mas só um pouco, não é necessário ter um prato enorme.
Depois um segundo prato, eu comeria carne. E como sobremesa um iogurte, um lácteo ou uma fruta". É a partir dessa estrutura que as entrevistadas tentam incorporar os princípios dietéticos de equilíbrio, variedade e moderação.

Além disso, a dicotomia almoço/refeição energética versus jantar/refeição leve é mais forte. Essa postura pode estar associada ao fato que na Espanha os horários das refeições são mais tardios (o almoço situa-se majoritariamente às 14 horas e o jantar às 21 horas), o que parece ir contra aquilo que é percebido como nutricionalmente adequado. SS (espanhola,19) usa essa lógica para definir uma alimentação saudável: "ter um tipo de alimentação ao meio-dia e outro à noite. Por exemplo, primeiro prato e segundo prato no almoço que te dê força sem te deixar pesado, e no jantar algo leve, peixe grelhado ou sopa".

As normas socioculturais e dietéticas do almoço interiorizadas pelas mulheres leigas espanholas correspondem às recomendações das nutricionistas entrevistadas. Contudo, a Estrategia NAOS não efetua recomendações sobre o almoço.

\section{Contexto brasileiro}

As brasileiras associam geralmente um "verdadeiro almoço" e uma "refeição equilibrada" a uma estrutura sincrônica, um prato composto de arroz, feijão, carne, salada e/ou legumes, acompanhado, às vezes, de uma sobremesa (principalmente uma fruta no caso da "refeição equilibrada") e/ou de um suco de frutas (Quadro 1). Para JM (brasileira, 25), um "verdadeiro almoço" é: "salada, legumes, carboidratos, proteínas, arroz, feijão e uma carne". Quando as informantes brasileiras falam de um prato de verdade, da comida de verdade, do essencial, do básico, elas se referem a esta combinação e seus discursos revelam uma dimensão simbólica, pois elas reivindicam esse prato como um dos elementos mais importantes da sua identidade alimentar brasileira. PA (nutricionista brasileira, 22) designa este prato como se fosse a comida por excelência:

Entrevistadora: você tem um alimento essencial?

PA: arroz, feijão e carne. Adoro comida.

Entrevistadora: como você imagina um verdadeiro almoço?

PA: é o que eu falei, arroz, feijão, uma carne, salada, legumes, eu gosto de comida mesmo.

Do ponto de vista dietético, a valorização deste modelo de refeição com sua multiplicidade de preparações é lembrada a partir da importância de se ter um prato colorido. As entrevistadas também têm interiorizadas prescrições dietéticas 
relativas às quantidades adequadas de cada componente (principalmente quatro colheres de sopa de arroz), assim como as proporções de arroz e feijão: “dois de arroz para uma de feijão". AV (nutricionista brasileira, 33) associa suas ideias sobre uma "refeição equilibrada" à sua profissão:

Coisa de nutricionista, hein? Tem que ter um prato de salada, variado, folhas e legumes crus, um mix de folhas, tanto verde claro como escuro, cruas. Tem que ter tomate, cenoura, beterraba, pode até ter um palmito para dar um gostinho. Uma fonte de carboidrato, um arroz, eu acho que o arroz é a base do carboidrato do brasileiro. E feijão, na proporção de dois para um, dois de arroz, um de feijão. Tem que ter proteina, pode ser carne, peixe, frango ou ovo. E de preferência assada ou grelhada, nada de à milanesa ou frita. Tem que ter um legume refogado. E o que faltou? Só. De sobremesa, fruta, de preferência fruta cítrica que ajuda na absorção do ferro ou um suco de laranja, de acerola, de caju e nada de açúcar.

A combinação arroz com feijão é percebida como a mais nutritiva e completa. Esse prato é às vezes descrito a partir de uma associação entre alimentos/normas socioculturais e nutrientes/ normas dietéticas, na medida em que as informantes citam os nutrientes correspondentes a cada alimento.

As entrevistadas também evocam as recomendações do discurso nutricional brasileiro a fim de legitimar a importância dietética desse prato. RS (brasileira, 29), orientada por uma nutricionista, destaca que ela deve comer esse prato indispensável para a alimentação saudável:

Como as nutricionistas falam, pelo menos cinco cores diferentes no prato. No Brasil, a gente sabe que o arroz com feijão é uma bela combinação. $\mathrm{Na}$ minha dieta não falta o arroz com feijão. Eu tento fazer equilibrado. Tento colocar uma pequena quantidade de carboidrato, uma grande quantidade de fibras. É importante não faltar arroz, feijão, carne, folhas de alface e legume.

De fato, nas recomendações das nutricionistas entrevistadas, assim como no Guia Alimentar para a População Brasileira, este formato de refeição é identificado como o modelo equilibrado (Quadro 1). As orientações deste guia, de caráter sobretudo qualitativo, exemplificam com fotografias o almoço recomendável como tendo uma estrutura sincrônica, quase sempre composta de arroz com feijão.

Existe, contudo, uma contradição, visto que quando uma parte das entrevistadas controla sua alimentação para emagrecer, elas reduzem o consumo de feijão. Nesse caso, o que é percebido como socialmente adequado e saudável não corresponde estritamente ao que é percebido como adequado para o controle do peso. SN (nutricionista brasileira, 38) declara: "apesar de eu não comer arroz e feijão todos os dias, pelo menos no almoço, eu acho que é o melhor, arroz, feijão, uma carne e uma salada, é o prato que deveria todo mundo comer, o mais equilibrado". Ela não come esse prato diariamente, porque ela engordaria. Dessa forma, este prato é uma norma social e é percebido como saudável, mas deve ser consumido de forma racional, seguindo determinadas regras como a moderação ou a substituição do arroz branco pelo integral, adaptação reivindicada como importante pelas brasileiras entrevistadas e que parece resultar de uma racionalização dietética da refeição.

\section{Discussão}

Neste artigo, foram pesquisadas as normas socioculturais e dietéticas do almoço - refeição que as francesas, espanholas e brasileiras entrevistadas consideram como a mais importante.

O "formato da refeição"15,16 é um elemento importante na apreensão das significações de uma "verdadeira refeição" e de uma "refeição equilibrada”. Existe uma articulação entre normas socioculturais e normas dietéticas e as fronteiras entre estes dois universos normativos parecem tênues. Por exemplo, quando as informantes se expressam sobre uma "verdadeira refeição", elas podem evocar aspectos relativos à "refeição equilibrada". Por outro lado, quando elas discorrem sobre uma alimentação saudável, elas recorrem a códigos socioculturais, como no caso de AV (nutricionista brasileira, 33) que sugere que "o arroz é a base do carboidrato do brasileiro”. De forma geral, suas descrições revelam convenções sociais definidas por sistemas normativos similares entre informantes de uma mesma nacionalidade. Apesar das nutricionistas terem uma visão mais medicalizada e mais conhecimentos nutricionais que as mulheres leigas, de um país ao outro as profissionais não pensam a refeição saudável da mesma forma. Seus discursos correspondem àqueles das mulheres leigas de sua própria nacionalidade. Dessa forma, o impacto sociocultural é importante, permitindo distinguir modelos para cada nacionalidade, interiorizados no decorrer da sua socialização no âmbito da família e da sociedade.

Confirmando estudos precedentes ${ }^{3,13}$, na Espanha e na França, as normas socioculturais e dietéticas do almoço referem-se geralmente a uma estrutura diacrônica. A lógica de construção dessas estruturas mostra-se, contudo, distinta 
entre os dois países. No Brasil, a refeição sincrônica com a presença do arroz com feijão é o modelo principal. Neste caso, a estrutura e a composição são indissociáveis, uma sendo o resultado da outra e vice-versa. Assim, embora se evidencie uma diminuição do consumo de arroz e feijão no Brasil $^{33}$, este estudo indica a presença sistemática desta combinação a nível normativo, revelando a permanência do sistema cultural em relação à alimentação de base, consumida cotidianamente por todas as classes sociais ${ }^{14}$.

Também se identifica a presença de alimentos que podem ser considerados como "marcadores identitários" - alimentos associados à identidade alimentar local -, assim como categorizações e usos que variam segundo o contexto, como no caso dos lácteos, do pão, do arroz e do feijão. A valorização e os usos socioculturais desses produtos influenciam os discursos sobre o saudável e o lugar concedido a eles na refeição percebida como saudável. Além disso, essas práticas e usos socioculturais modelam as categorizações nutricionais das nutricionistas entrevistadas. Por exemplo, para as brasileiras, as leguminosas, representadas sobretudo pelo feijão que é sistematicamente consumido com arroz, são associadas às proteínas, enquanto na França e na Espanha, onde as leguminosas podem ser consumidas sem acompanhamento de cereais, estes alimentos são frequentemente assimilados ao grupo dos carboidratos e/ou cereais. Também existem diferenças nos discursos de saúde pública. Nas 12 decisões saudáveis propostas pela Estrategia NAOS, as leguminosas são associadas aos carboidratos e, até 2017, o PNNS incluía as leguminosas nas recomendações dos carboidratos.

Nos três países, observa-se a presença de normas dietéticas gerais, como a variedade, o equilíbrio e a moderação - normas estas cada vez mais difundidas com a medicalização da alimentação ${ }^{6}$, sustentadas por organismos internacionais ${ }^{9} \mathrm{e}$ interiorizadas por indivíduos de diferentes contextos socioculturais $^{34,35}$. Tais normas são, porém, incorporadas a partir de estruturas existentes nos modelos alimentares locais. Dentro de cada realidade sociocultural, esses princípios dietéticos implementam-se de formas particulares. As diferenças são observáveis nas recomendações das nutricionistas e de saúde pública. Como sugere Poulain ${ }^{3}$, a comunidade médica e as instâncias políticas dão, assim, suporte científico às normas socioculturais. Este diálogo com as culturas locais é de fato incentivado pela Organização Mundial de Saúde ${ }^{9}$. O PNNS, o Guia Alimentar para a População Brasileira e, de forma menos importante, a Estrategia Naos, buscam esta aproximação e reivindicam a cultura alimentar de seus países como estratégia para compor suas recomendações nutricionais.

Fournier" 36 evoca um "relativismo nutricional”. De acordo com este sociólogo, para além de um consenso sobre as percepções de algumas normas dietéticas, determinados fenômenos operam-se na escala sociocultural, modelando a recepção e a implementação destas normas. Esse conceito parece pertinente para abarcar as observações realizadas no presente estudo. Por exemplo, no caso do consumo de lácteo no final da refeição. Se para as brasileiras a norma relativa a evitar esse consumo parece ter uma justificação fisiológica, assim como parece estar bem integrada nas mensagens nutricionais e práticas socioculturais cotidianas, para as francesas trata-se de uma prática saudável, socialmente valorizada, a ser conservada no cotidiano e prescrita no âmbito da educação nutricional. De fato, determinadas lógicas nutricionais somente têm sentido dentro e pela realidade sociocultural na qual são construídas. Existe, assim, um ajustamento, uma relação recíproca complexa entre normas dietéticas e normas socioculturais. Além disso, constatou-se que outros discursos, associados a outros universos normativos, também influenciam a percepção da refeição "saudável” e/ou adequada, como por exemplo aqueles associados à norma estética da magreza. Como se evidenciou no caso brasileiro, a combinação de arroz com feijão é percebida como saudável, mas nem sempre adequada em vista do emagrecimento. Esse ajustamento de diferentes normas constrói distintas formas de pensar a alimentação e a refeição saudáveis em função dos indivíduos e contextos socioculturais, até mesmo entre as nutricionistas. De acordo com a realidade sociocultural, o discurso médico e nutricional constrói-se, assim, segundo lógicas distintas ${ }^{37}$. Esses resultados alinham-se com as observações de Leeman et al..$^{38}$ relativas à existência de diferentes concepções de alimentação saudável entre médicos de diferentes países. Pode-se, então, afirmar que os discursos e normas dietéticas também são construções socioculturais, e a compreensão do comer saudável deve implicar um exercício de contextualização histórica e sociocultural ${ }^{9}$.

Finalmente, é importante ressaltar que os dados deste artigo se referem às normas do almoço e que estas não correspondem necessariamente às práticas das informantes. Como constatam outros trabalhos ${ }^{3,13,14}$, existem disparidades entre normas e práticas, visto que as últimas são mais influenciadas pelas limitações materiais. Para além das normas, existe o regime factível, caracterizado pelas possibilidades que os sujei- 
tos encontram em seus cotidianos, inscritos em realidades singulares ${ }^{21}$. As informantes, inclusive as leigas, possuem noções concretas sobre como uma refeição deve estar estruturada, não somente do ponto de vista sociocultural. Elas têm interiorizado normas dietéticas que estão conformes ao discurso nutricional. Existem, porém, disparidades entre essas normas e suas práticas, confirmando que ter conhecimento nutricional não é uma condição suficiente para a implementação de práticas percebidas como "saudáveis" e que os indivíduos não são movidos por uma única forma de racionalidade ${ }^{2,7}$. As entrevistadas indicam, por exemplo, que as limitações financeiras e aquelas impostas pelo trabalho, estudos ou vida familiar e social influenciam suas práticas alimentares, tanto em relação à preparação das refeições como em relação ao seu consumo nos níveis temporal, estrutural, espacial e social. Neste contexto, elas se encontram, frequentemente, em uma situação na qual elas devem negociar com suas normas (socioculturais e dietéticas) e as limitações confrontadas no cotidiano.

Este trabalho apresenta limitações relativas à metodologia e amostragem usadas, influenciando a representatividade dos resultados. Os países não correspondem a um conjunto homogêneo de indivíduos. Na França, na Espanha e no Brasil, existem diferenças regionais relacionadas à alimentação, bem como segundo variáveis sociais como a classe social e o gênero ${ }^{3,13,14,20}$. Uma abordagem quantitativa e/ou considerando outros grupos, cidades ou a zona rural poderia abarcar a complexidade dos contextos nacionais e verificar a extensão dos resultados em uma amostra mais ampla.

\section{Conclusão}

As concepções de almoço das nutricionistas e mulheres leigas francesas, espanholas e brasileiras entrevistadas revelam que cada nacionalidade possui códigos particulares que definem as modalidades de refeição do ponto de vista sociocultural e dietético. A definição de refeição "saudável” depende de fatores que vão do nutricional às dimensões socioculturais e simbólicas vinculadas a cada modelo alimentar, determinando temporalidades, usos e a classificação dos alimentos. As prescrições nutricionais são reinterpretadas no seio dos contextos socioculturais e redefinidas pelos atores sociais, inclusive os nutricionistas. Os resultados deste trabalho permitem, assim, questionar a imposição de normas dietéticas de maneira dogmática. Além disso, reforçam a ideia de que os discursos nutricionais devem ser pensados a partir de cada contexto e considerando a situação de cada indivíduo, abrangendo as dimensões socioculturais e simbólicas relacionadas ao comer. Estes resultados também sugerem que futuros estudos, baseados em metodologias qualitativas, devem analisar as barreiras que os indivíduos encontram para seguir as normas socioculturais e dietéticas, o que permitirá compreender as práticas alimentares afim de propor estratégias eficazes.

Outra contribuição deste estudo reside na abordagem comparativa inter e intranacional. Este enfoque revela-se interessante para a compreensão dos modelos alimentares, frente a um contexto caracterizado por modificações sociais que acentuaram uma articulação entre o global e o local. A comparação também desvenda elementos do cotidiano que são vistos como "naturais", mas que são reveladores de sistemas normativos socioculturais. Finalmente, a comparação internacional das normas dietéticas evidencia o que é singular a cada contexto, questionando, assim, a uniformidade dos discursos médico-científicos ocidentais. Embora este tipo de abordagem seja escasso, ele poderia ser usado para aprofundar a análise de outras dimensões da relação alimentação-saúde, como as relações complexas entre o prazer e o saudável.

\section{Agradecimentos}

Agradeço ao Observatorio de la Alimentación da Universitat de Barcelona (España) onde esta pesquisa também foi realizada através de um doutorado em cotutela com a Université de Toulouse - Jean-Jaurès. 


\section{Referências}

1. Mauss M. Les techniques du corps. In: Mauss M, organizador. Sociologie et Anthropologie. Paris: PUF; 2009.

2. Fischler C. L'Homnivore. Paris: Odile Jacob; 1990.

3. Poulain JP. Manger Aujourd'hui: attitudes, normes et pratiques. Toulouse: Privat; 2002.

4. Scrinis G. Nutritionism: The Science and Politics of Dietary Advice. Nova York: Columbia University Press; 2013.

5. Viana MR, Neves AS, Camargo Junior KR, Prado SD, Mendonça ALO. A racionalidade nutricional e sua influência na medicalização da comida no Brasil. Cien Saude Colet 2017; 22(2):447-456.

6. Gracia M. Comer bien, comer mal: la medicalización de la alimentación. Salud Publica Mex 2007; 49(3):236-242.

7. Poulain JP. Sociologie de l'obésité. Paris: PUF; 2009.

8. Brasil. Ministério da Saúde (MS). Guia alimentar para a população brasileira. Brasília: MS; 2014.

9. World Health Organization (WHO). Alimentation saine [Internet]. 2015 [acessado 2016 jul 14]. Disponível em: http://www.who.int/mediacentre/factsheets/ fs394/fr/.

10. Kraemer FB, Prado SD, Ferreira FR, Carvalho MCVS. O discurso sobre a alimentação saudável como estratégia de biopoder. Physis 2014; 24(4):1337-1359.

11. Gaspar MC, Juzwiak C, Muñoz A, Larrea C. Las relaciones entre salud y alimentación. Una lectura antropológica. In: Odela, organizador. Polisemias de la alimentacion: salud, desperdicio, hambre y patrimonio. Barcelona: Universitat de Barcelona; 2018. p.53-76.

12. Vasconcelos FAG, Calado CLA. Profissão nutricionista: 70 anos de história no Brasil. Rev Nutr 2011; 24(4):605-617.

13. Odela. La alimentación y sus circunstancias: placer, conveniencia y salud. Barcelona: Alimentaria; 2004.

14. Barbosa L. Feijão com arroz e arroz com feijão: o Brasil no prato dos brasileiros. Horiz Antropol 2007; 13(28):87-116.

15. Herpin N. Le repas comme institution: compte rendu d'une enquête exploratoire. Rev Fr Sociol 1988; 29(3):503-521.

16. Mäkelä J, Kjaernes U, Pipping EM, Fürst E, Gronow J, Holm L. Nordic Meals: Methodological Notes on a Comparative Survey. Appetite 1999; 32(1):73-79.

17. Douglas M. Les estructures du culinaire. Communications 1979; 31:145-170.

18. Mäkelä J. Repas (statut social du). In: Poulain JP, organizador. Dictionnaire des cultures alimentaires. Paris: PUF; 2012. p. 1142-1147.

19. Saint Pol T. Repas. In: Poulain JP, organizador. Dictionnaire des cultures alimentaires. Paris: PUF; 2012.p. 1137-1142.

20. Kahma N, Mäkelä J, Niva M, Lund T. Associations between meal complexity and social context in four Nordic countries. Anthropol Food 2014; S10:aof.7666.

21. Danesi G. Manger ensemble: les formes et les significations de la commensalité chez des jeunes adultes français, allemands et espagnols d'aujourd'hui [tese]. Paris: EHESS; 2013.

22. Murcott A. On the social significance of «cooke dinner» in South Wales. Soc Sci Inf 1982; 21(4-5):677-696.

23. Collaço JH. Um Olhar Antropológico sobre o Hábito de Comer Fora. Campos 2003; 4:171-194.
24. Poulain JP. Combien de repas par jour? Normes culturelles et normes médicales en Polynésie Française. $J$ Anthropol 2006; 106-107:245-268.

25. Tibère L, Rochedy A, Sarrat C. Le goûter résiste à la nutritionnalisation. Cah Nutr Diet 2018; 54(4):232239.

26. Grignon C. Une sociologie des normes diététiques est-elle possible? Le cas de l'obésité. La vie des idées 2015; 1-9.

27. Blanchet A, Gotman A. L'entretien. Paris: Armand Colin; 2005.

28. Vigour C. La comparaison dans les sciences sociales. Paris: La Découverte; 2005.

29. Agencia Española de Seguridad Alimentaria y Nutrición (AESAN). Ministerio de Sanidad, Servicio Social e Igualdad. Estrategia para la nutrición, actividad fisica $y$ prevención de la obesidad (Estrategia NAOS). Madrid: AESAN; 2005.

30. Sobal J. Cultural comparison research designs in food, eating, and nutrition. Food Qual Prefer 1998; 9(6):385-392.

31. Cairns K, Johnston J. Food and femininity. New York: Bloomsbury; 2015.

32. Conselho Federal de Nutrição. Estatísticas [Internet]. 2016 [acessado 2016 out 15]. Disponível em: http:// www.cfn.org.br/index.php/estatistica/.

33. Instituto Brasileiro de Geografia e Estatística (IBGE). Pesquisa de Orçamentos Familiares 2008-2009: aquisição alimentar domiciliar per capita, Brasil e Grandes Regiões. Rio de Janeiro: IBGE; 2010.

34. Paquette MC. Perceptions de l'alimentation saine: état actuel des connaissances et lacunes au niveau de la recherche. Can J Public Health 2005; 96(3):S16-S21.

35. European Commission. Health and Food. Special Eurobarometer 2006; 246.

36. Fournier T. Face à l'injonction diététique: un relativisme nutritionnel en France [Internet]. SociologieS; 2014. [acessado 2016 fev 10]. Disponível em: http:// journals.openedition.org/sociologies/4628.

37. Payer L. Medicine \& Culture. New York: Henry Holt and Company; 1996.

38. Leeman R, Fischler C, Rozin P. Medical doctors' attitudes and beliefs about diet and health are more like those of their lay countrymen (France, Germany, Italy, UK and USA) than those of doctors in other countries. Appetite 2011; 56(3):558-563.

Artigo apresentado em 27/08/2019

Aprovado em 17/04/2020

Versão final apresentada em 19/04/2020

Editores-chefes: Romeu Gomes, Antônio Augusto Moura da Silva 